\title{
Over Effective Control of Glycemic Levels Could Cause Cognitive Decline in Diabetic Geriatric Population
}

\author{
Miguel Ángel Carreiro Alonso, PhD1*; José Manuel Mayán Santos, PhD1; Martin \\ Iglesias Vilanova, $\mathrm{PhD}^{1}$; Antonio Domingo Pose Reino, $\mathrm{PhD}^{2}$
}

1Santiago de Compostela University, Spain

2Santiago de Compostela Clinical University Hospital Complex, Spain

\begin{abstract}
Introduction: Cognitive impairment and dementia constitute an important health problem in the geriatric population. Nowadays, the prevalence of these alterations has increased, especially as a result of progressively longer life expectancy. Different studies have shown the risk of hyperglycemia and hypoglycemia and its association with cognitive function in the population with diabetes.

The objective of this study is to establish the physical dependence level and the cognitive impairment degree as well as its potential association with diabetes and hypoglycemia risk.

Methods: A multicenter cross-observational study was performed with the participation of 654 institutionalized residents of nursing homes to analyse anthropometric data, prevalence of diabetes, disability, and cognitive impairment associated with this metabolic disease.

Results: The average age of the sample was 82.4 years. The prevalence of diabetes amounted to $23.5 \%$. Moreover, $7.8 \%$ of them remained with $\mathrm{HbA1}>>8.5 \%$, while $54.2 \%$ presented with $\mathrm{HbA} 1 \mathrm{c} \leq 6.5 \%$ with a high risk of hypoglycemia. The average disability of the global sample was moderate with an average of 43.8 points on the Barthel Index and the average of mistakes in the Pfeiffer test was 5.5, showing a mild cognitive impairment. We found a significant association between $\mathrm{HbA1}$ c less than $6 \%$ and higher cognitive impairment in diabetic cases (P $=0.04)$. Conclusion: Diabetes control in the studied population could be too strict, and consequently, hypoglycemia in these patients could play a role in the major decline of cognitive function. Therefore, avoiding treatments that could lead to hypoglycemia in these patients could be very important. The aim of the treatment of diabetes in elderly patients is focused on stabilization, prevention of acute complications, and improving the quality of life.
\end{abstract}

\section{Introduction}

Cognitive impairment and dementia constitute an important health problem in the geriatric population. Nowadays, the prevalence of these alterations has increased, especially as a result of progressively longer life expectancy [1]. In Spain, type 2 Diabetes Mellitus (T2DM) prevalence in the population aged over 65 years is between 10 to $15 \%$, and more than $20 \%$ at 80 years [2]. Several studies indicate that the risk of cognitive impairment related to T2DM increases with age [3-5]. The brains of older people are especially vulnerable to hypoglycemia effects [6]. After every hypoglycemic episode, major cognitive changes could occur [7]. Diabetic patients do not usually obtain satisfactory results in neuropsychological tests, which particularly involve attention and executive functions [8].

Objectives for glycated hemoglobin (HbA1c) in older adults should generally be $7.5 \%$ to $8 \%$. However, an $\mathrm{HbA} 1 \mathrm{c}$ level between $7 \%$ and $7.5 \%$ may be acceptable when healthy older adults without comorbidities and good functional status are included. Higher HbA1c levels (> 8.5\%) are acceptable for older adults with multiple comorbidities and short life expectancy (usually less than one year) [9]. Moreover, there is potential harm in lowering HbA1c to less than $6.5 \%$ in older adults with T2DM $[10,11]$. One of the main characteristics of the geriatric population is their heterogeneity, presenting high comorbidities, changes in body composition, and an increased level of physical dependence and cognitive impairment; these factors often cause nutritional problems and a propensity to develop T2DM and its complications [12,13]. Due to these syndromes, the need of self-care and the probability of institutionalization increase. T2DM is one of the pathologies that require more care in these centers [14].

The objective of this study is to establish the physical dependence level and the cognitive impairment degree, as well as its potential association with T2DM and hypoglycemia risk related to a strict control of HbA1c levels required by this population group.

\section{Materials and Methods}

A multicenter cross-observational study was performed with the participation of 654 patients from six geriatric and gerontological care centers in Galicia (Spain), from October 2012 to March 2016. Nursing homes were selected by geographical location and volume of patients. All patients were informed in detail about the aims of the present study and its interventions, including the review of their clinical history, completion of complementary tests and scales. Informed consent was signed by every participant or legally authorized representative and the rights of the participants were protected throughout the study.

The following inclusion criteria were used: Volunteer participants living in nursing homes for more than six months before the commencement of the study signed an informed consent form in accordance with the informed consent law. In the case of patients with any grade of cognitive impairment, their legal guardians signed the informed consent form on their behalf. The exclusion criteria comprised the cases whose clinical history did not meet all the study variables, the patients who had been residing in the studied geriatric centers for less than six months at the time of commencement of the study, and the persons with guardianship in Foundations whose policies did not allow participation in studies.

For all patients the following information was obtained from their clinical history: age, sex, Body Mass Index $\left(\mathrm{Kg} / \mathrm{m}^{2}\right)$, Diabetes Mellitus diagnosis, diabetes treatment, and diagnosed macrovascular and microvascular complications. When patients were included in the study, a functional and cognitive geriatric assessment was made using the Pfeiffer test 


\begin{tabular}{|c|c|c|c|c|c|c|}
\hline \multirow[t]{2}{*}{ Variable } & \multicolumn{3}{|c|}{ Diabetics $(n=154)$} & \multicolumn{3}{|c|}{ Non-diabetics $(n=500)$} \\
\hline & \multirow{2}{*}{$\begin{array}{c}\text { Total } \\
81.3( \pm 8.2)\end{array}$} & \multicolumn{2}{|c|}{ Women $(n=106)$} & \multirow{2}{*}{$\begin{array}{c}\text { Total } \\
82.8( \pm 9.1)\end{array}$} & \multicolumn{2}{|c|}{ Women $(n=350)$} \\
\hline Average Age (years) (Standar Deviation) & & $81.7( \pm 8.2)$ & P-value & & $84.5( \pm 8.1)$ & P-value \\
\hline $\begin{array}{l}65-75 \text { years } \\
76-85 \text { years } \\
>85 \text { years }\end{array}$ & $\begin{array}{l}20.1 \%(n=31) \\
50.0 \%(n=77) \\
29.9 \%(n=46)\end{array}$ & $\begin{array}{l}19.8 \%(n=21) \\
48.1 \%(n=51) \\
32.1 \%(n=34)\end{array}$ & 0.05 & $\begin{array}{l}17.9 \%(n=89) \\
39.0 \%(n=194) \\
43.1 \%(n=217)\end{array}$ & $\begin{array}{l}11.5 \%(n=40) \\
39.1 \%(n=137) \\
49.4 \%(n=173)\end{array}$ & 0.02 \\
\hline Diabetes Prevalence (\%) & $23.5 \%(n=154)$ & $23.2 \%(n=106)$ & & N/A & N/A & \\
\hline $\begin{array}{l}\text { Diabetes treatment } \\
\qquad \begin{array}{l}\text { Oral hypoglycemic drugs } \\
\text { Insulin therapy } \\
\text { Oral treatment with insulin } \\
\text { No treatment }\end{array}\end{array}$ & $\begin{array}{l}51.3 \%(n=79) \\
22.7 \%(n=35) \\
12.3 \%(n=19) \\
13.7 \%(n=21)\end{array}$ & $\begin{array}{l}50.9 \%(n=54) \\
23.6 \%(n=25) \\
11.3 \%(n=12) \\
14.2 \%(n=15)\end{array}$ & 0.76 & $\begin{array}{l}\text { N/A } \\
\text { N/A } \\
\text { N/A } \\
\text { N/A }\end{array}$ & $\begin{array}{l}\text { N/A } \\
\text { N/A } \\
N / A \\
N / A\end{array}$ & \\
\hline $\begin{array}{l}\text { HbA1c levels } \\
\qquad \begin{aligned} H b A 1 c \leq 6 \% \\
H b A 1 c 6.1-6.4 \% \\
\text { HbA1c } 6.5-7.0 \% \\
\text { HbA1c } 7.1-8.5 \% \\
\text { HbA1c }>8.5 \%\end{aligned}\end{array}$ & $\begin{array}{l}37.0 \%(n=57) \\
15.6 \%(n=24) \\
16.2 \%(n=25) \\
23.4 \%(n=36) \\
7.8 \%(n=12)\end{array}$ & $\begin{array}{l}41.5 \%(n=44) \\
19.8 \%(n=21) \\
13.2 \%(n=14) \\
18.9 \%(n=20) \\
6.6 \%(n=7)\end{array}$ & 0.20 & $\begin{array}{l}86.6 \%(n=433) \\
8.0 \%(n=40) \\
4.0 \%(n=20) \\
1.0 \%(n=5) \\
0.4 \%(n=2)\end{array}$ & $\begin{array}{l}87.7 \%(n=307) \\
8.6 \%(n=30) \\
2.3 \%(n=8) \\
1.1 \%(n=4) \\
0.3 \%(n=1)\end{array}$ & 0.28 \\
\hline $\begin{array}{l}\text { Barthel Index average (points). } \\
\qquad \begin{array}{l}\leq 15 \text { points } \\
20-35 \text { points } \\
40-55 \text { points } \\
60-95 \text { oints } \\
100 \text { points }\end{array}\end{array}$ & $\begin{array}{l}39.4( \pm 35.3) \\
40.3 \%(n=62) \\
12.3 \%(n=19) \\
16.2 \%(n=25) \\
22.1 \%(n=34) \\
9.1 \%(n=14)\end{array}$ & $\begin{array}{l}48.1 \%(n=51) \\
11.3 \%(n=12) \\
15.1 \%(n=16) \\
17.9 \%(n=19) \\
7.6 \%(n=8)\end{array}$ & 0.05 & $\begin{array}{l}45.2( \pm 36.0) \\
32.8 \%(n=164) \\
16.4 \%(n=82) \\
11.0 \%(n=55) \\
26.8 \%(n=134) \\
13.0 \%(n=65)\end{array}$ & $\begin{array}{l}34.6 \%(n=121) \\
18.3 \%(n=64) \\
11.7 \%(n=41) \\
27.1 \%(n=95) \\
8.3 \%(n=29)\end{array}$ & 0.01 \\
\hline $\begin{array}{l}\text { Average of mistakes in Pfeiffer test } \\
\text { Normal cognitive function } \\
\text { Mild cognitive impairment } \\
\text { Moderate cognitive } \\
\text { impairment } \\
\text { Severe cognitive impairment }\end{array}$ & $\begin{array}{l}5.3( \pm 4.1) \\
37.1 \%(n=57) \\
4.5 \%(n=7) \\
9.7 \%(n=15) \\
48.7 \%(n=75)\end{array}$ & $\begin{array}{l}36.8 \%(n=39) \\
2.8 \%(n=3) \\
7.6 \%(n=8) \\
52.8 \%(n=56)\end{array}$ & 0.03 & $\begin{array}{l}5.6( \pm 4.0) \\
31.2 \%(n=156) \\
4.4 \%(n=22) \\
18.2 \%(n=91) \\
46.2 \%(n=231)\end{array}$ & $\begin{array}{l}26.9 \%(n=94) \\
2.5 \%(n=9) \\
20.6 \%(n=72) \\
50.0 \%(n=175)\end{array}$ & 0.01 \\
\hline
\end{tabular}

[15] (cognitive assessment) and the Barthel index [16] (functional assessment). A blood sample was also collected at that time to obtain $\mathrm{HbA} 1 \mathrm{c}$ level.

Functional status was evaluated using the Barthel Index that measured the basic activities of daily living. This index assesses several physical dependence domains. Scores below 20 points identify total dependence, scores between 20 to 35 points show severe dependence, and scores between 40 to 55 and 60 to 95 points indicate moderate and mild dependence, respectively; 100 points identify that the patients are physically independent.

Cognitive status was evaluated using the Pfeiffer test. It is used as a screening tool that can help to detect cognitive impairment. It has sensitivity close to $70 \%$ and a very high specificity close to $95 \%$. Scores higher than 8 mistakes identify severe cognitive impairment, and scores between 5 to 7 and 3 to 4 mistakes show moderate and mild cognitive impairment, respectively. Normal cognitive status is identified by 0 to 2 mistakes.

A descriptive analysis was used. Qualitative variables were obtained by means of proportions calculation. Quantitative variables were obtained by averages, standard deviation, and maximum and minimal ranges.

As a test of normality in continuous variables, Kolmogorov-Smirnov's test with Lillefors's correction and Shapiro-Wilk test were used. The normal variables were expressed as an average and standard deviation, and not Gaussian variables as a median and range. To compare variables Chi square test, Mann Whitney $\mathrm{U}$ test, and Kruskal-Wallis test were used. The analyses were performed using SPSS V. 22 for Windows.

\section{Results}

The number of residents in the selected centers was 925 potential candidates, of which, 654 cases fulfilled all inclusion criteria and none of the exclusion criteria. The average age of the sample was $82.4( \pm 8.9)$ years. There was a predominance of women as they accounted for $69.7 \%(n=$ 455) of the sample (Table 1).

Diabetic cases had an average of $5.3 \pm 4.1$ mistakes in the Pfeiffer test. Non-diabetic cases had $5.6 \pm 4.0$ mistakes. Only $33 \%(n=216)$ of the participants obtained a normal cognitive status. $47.2 \%(n=305)$ had a severe cognitive impairment. By sexes, $73.8 \%(n=225)$ were women, who had a higher cognitive impairment grade than men $(P=0.03)$.

Cognitive status worsened with age. $52.8 \%(n=47)$ of cases aged between 65 to 75 years and $67.1 \%(n=153)$ between 86 to 95 years had moderate or severe cognitive impairment. Patients treated with insulin had a worse cognitive status $(P=0.02) .57 .4 \%(n=20)$ of diabetic patients treated with insulin had severe cognitive impairment. In our study, there

Table 2. Variables correlated with $\mathrm{HbA} 1 \mathrm{c} \leq 6 \%$ in diabetic cases

\begin{tabular}{|c|c|c|}
\hline \multicolumn{2}{|l|}{$\mathrm{HbA} 1 \mathrm{c} \leq 6 \%$ in diabetic cases } & $P$ value \\
\hline $\begin{array}{r}\text { Advanced age } \\
\qquad 80 \text { years } \\
>80 \text { years }\end{array}$ & $\begin{array}{l}21.1 \%(n=12) \\
78.9 \%(n=45)\end{array}$ & 0.02 \\
\hline $\begin{array}{l}\text { Cognitive Function } \\
\qquad \begin{array}{l}\text { Normal cognitive function } \\
\text { Mild cognitive impairment } \\
\text { Moderate cognitive } \\
\text { impairment } \\
\text { Severe cognitive impairment }\end{array}\end{array}$ & $\begin{array}{l}38.6 \%(n=22) \\
1.8 \%(n=1) \\
5.3 \%(n=3) \\
54.4 \%(n=31)\end{array}$ & 0.02 \\
\hline $\begin{array}{l}\text { Barthel Index (points) } \\
\qquad \begin{aligned} & 15 \text { points } \\
& 20-35 \text { points } \\
& 40-55 \text { points } \\
& 60-95 \text { points } \\
& 100 \text { points }\end{aligned}\end{array}$ & $\begin{array}{l}43.9 \%(n=25) \\
14.0 \%(n=8) \\
22.8 \%(n=13) \\
15.8 \%(n=9) \\
3.5 \%(n=2)\end{array}$ & 0.005 \\
\hline
\end{tabular}


Table 3. Barthel Index in diabetic women cases with $\mathrm{HbA1} \leq \leq \%$

\begin{tabular}{|l|c|c|}
\hline Barthel Index (points) & $\begin{array}{c}\text { Diabetic women with } \\
\text { HbA1c } \leq 6 \%(n=44)\end{array}$ & p-value \\
\hline$\leq 15$ points & $88.0 \%(n=22)$ & 0.02 \\
$20-35$ points & $62.5 \%(n=5)$ & \\
$40-55$ points & $84.6 \%(n=11)$ & \\
$60-95$ points & $66.6 \%(n=6)$ & \\
100 points & $0 \%(n=0)$ & \\
\hline
\end{tabular}

was no association between oral antidiabetic drugs and cognitive impairment ( $p$ value $>0.05) .40 .5 \%(n=32)$ of diabetic patients treated with oral antidiabetic drugs had severe cognitive impairment. $54.4 \%(n=31)$ of diabetic patients with $\mathrm{HbA} 1 \mathrm{c}$ levels $\leq 6 \%$ had severe cognitive impairment. A significant association between $\mathrm{HbA} 1 \mathrm{c}$ levels $\leq 6 \%$ and severe cognitive impairment $(P=0.04)$ in diabetics was observed, but no such association was found in non-diabetic patients. $38.6 \%(n=22)$ of documented diabetic patients with levels of $\mathrm{HbA} 1 \mathrm{c} \leq 6 \%$ obtained a normal cognitive status in the Pfeiffer test. On the other hand, 54.4\% $(n=31)$ had severe cognitive impairment and $\mathrm{HbA} 1 \mathrm{c}$ levels compatible with high risk of hypoglycemia. In contrast, out of the total number of patients with moderate or severe cognitive impairment, only $6.6 \%(n=7)$ of the cases presented with $\mathrm{HbA} 1 \mathrm{c}$ levels above $8.5 \%$. Non-diabetic cases with low HbA1c levels (under 6.5\%) and severe cognitive impairment represent $46.4 \%(n=217)$. We found no association between low $\mathrm{HbA} 1 \mathrm{c}$ levels and cognitive impairment $(P=0.89)$.

Advanced age $(P=0.02)$ and moderate-severe cognitive impairment $(P=0.02)$ were the variables associated with an intense glycemic control and a high risk of developing hypoglycemia. In contrast, the non-diabetic group was not significantly associated with these outcomes (Table 2).

This study did not show an association between $\mathrm{HbA} 1 \mathrm{c}$ low levels and general functional status (p.value $>0.05$ in General Barthel Index), but it showed association between $\mathrm{HbA1c}$ low levels and functional dependence in female diabetic patients $(P=0.02)$ (Table 3$)$. Low scores in the Barthel Index were also associated with a high risk of developing hypoglycemia $(P=0.005)$.

\section{Discussion}

In this research, we studied the relationship of T2DM with cognitive impairment in the population living in nursing homes in Galicia (Spain). T2DM prevalence was $23.5 \%$. These results show that T2DM prevalence is high compared with the community, according to a variety of studies that indicate a prevalence between 10-20\% [17-19], but similar to that found in geriatric population studies.

Most cases were women, who presented with worse cognitive status and higher physical dependence than men. In this study, females with low HbA1c levels have functional dependence correlation, but not in males. This mechanism could be possible because females have a longer age than males, and advanced age is associated with a higher functional dependence and maintaining low blood glucose levels for a long time. The Pfeiffer test was selected as the scale to assess cognitive status. It has sensitivity close to $70 \%$ and a very high specificity close to $95 \%$, being a fast screening tool to evaluate cognitive changes. Our study did not attempt to diagnose dementia, for which more tools were needed. We wanted to know the degree of cognitive deterioration. For this purpose, the Pfeiffer test was an adequate indicator, as it had been validated and clinically contrasted. Besides, different experts in the field of geriatrics have agreed on using simple tests that require little time for their realization, especially for screening; and the Pfeiffer test meets these requirements [20].

Elderly people with diabetes are vulnerable to hypoglycemia with the development neuroglycopenic symptoms like confusion and disorientation. Hospital admissions due to severe hypoglycemia are $40 \%$ higher than those for hyperglycemia in geriatric patients [21,22]. Patients with dementia or cognitive impairment were significantly more susceptible to hospitalization as a result of hypoglycemia than the patients with normal cognitive function $[6,23]$. Hypoglycemia associated with diabetes treatments with secretagogues or insulin is more frequent and more severe in the elderly and has potentially serious consequences, such as falls, cognitive impairment, arrhythmias or cardiovascular events [24]. The elderly treated with insulin have a higher risk of cognitive impairment and dementia because they have a long disease evolution and have a suboptimal control of glycemic targets [21]. The results of our study show a link between the treatment with insulin and a higher rate of severe cognitive impairment compared to the treatment with oral antidiabetics where no association was found.

Cognitive impairment and dementia constitute an important health problem in the geriatric population. In particular, the elderly diabetics presented with recurrent hypoglycemia have higher mortality rates and an increased risk of cognitive decline and dementia. Moreover, the brains of the elderly population are more vulnerable to the effects of these hypoglycemias.

We found that more than half of the diabetic patients had $\mathrm{HbA} 1 \mathrm{c}$ values below $6.5 \%$, and only $23.4 \%$ of them had levels between $7 \%$ and $8.5 \%$, which was recommended by the different international associations as good control in this frail and complex population [9]. These findings demonstrate a potentially harmful aggressive hypoglycemic therapeutic approach in these patients. Therefore, specific treatment strategies should be proposed for glycemic control to limit metabolic decompensation and avoid the risk of hypoglycemia, and $\mathrm{HbA} 1 \mathrm{c}$ targets under $8.5 \%$ are made acceptable for older adults with multiple comorbidities and limited life expectancy [25]. In our study, HbA1c levels were lower in demented patients, who were more prone to the consequences of hypoglycemia; there were signs of overtreatment in the population as a whole. Cognitively impaired and demented patients are more vulnerable to hypoglycemia, which itself represents a major risk factor for further cognitive decline $[5,6,12,24]$. Atypical clinical presentation of hypoglycemia makes an early diagnosis of hypoglycemia and their harmful consequences are extremely difficult in demented and frail patients.

Our results demonstrate that there could be an association between the levels of $\mathrm{HbA} 1 \mathrm{C}<6 \%$ in diabetics and severe cognitive impairment. The latest recommendations of the American Diabetes Association [10] establish that older adults have a high risk of hypoglycemia, citing high morbidity, insulin therapy or progressive renal failure among the causes of such increased risk. In addition, with aging, the cognitive deficit rates increase, leading to a deterioration of self-care, poor glucose controls or insulin dose adjustment.

These deficits have been associated with an increased risk of hypoglycemia; and severe hypoglycemia is associated with an increased cognitive impairment proportion. It is necessary that all healthcare teams identify any cognitive status modification in diabetic patients, emphasizing the importance of hypoglycemia prevention. Similarly, antidiabetic treatments need to be adapted to the needs and daily activities of this complex population $[16,26]$. The objectives of glycemic control should be patient-centered and individualized in each case, instead of trying to achieve strict control of HbA1c levels.

Furthermore, a meta-analysis published in 2016 shows the bi-directional relationship between cognitive impairment and hypoglycemia in older patients and concludes that glucose-lowering therapy should be carefully tailored and monitored in older patients who are susceptible to cognitive decline [27].

The objective treatment according to different guide experts should be directed to the symptoms relief, preventing long-term complications, and avoiding hypoglycemia. The functional status of each patient should be determined, with special emphasis on the presence of cognitive impairment or dementia, where HbA1c targets should be around 8.5\% [21].

All health personnel working at nursing homes centers should pay attention on identifying both physical and cognitive modifications in diabetic patients, anticipating hypoglycemias or any other symptomatology related with $\mathrm{T} 2 \mathrm{DM}$, and suitable treatment to their daily activities and needs, rather than aiming at a specific HbA1c [26]. 
As study limitations, we found that age was a risk factor for cognitive decline in the $\mathrm{HbA} 1 \mathrm{c}<6.5 \%$ group. However, there was the possibility that these patients had $\mathrm{HbA} 1 \mathrm{c}<6.5 \%$ for longer time than their younger counterparts, indicating that the correlation with cognitive decline might be age or maintaining low blood glucose levels for a long time.

In this cross-sectional study, no previous information regarding glucose levels before the study was collected and no analysis was performed to determine which variables were associated with rigorous T2DM control and the risk of developing hypoglycemia. This was a limitation to our work, which would have provided important information about glycemic control and its complications.

\section{Conclusion}

The management and treatment of the studied institutionalized geriatric diabetic population in our region could be too strict. Consequently, hypoglycemia in these patients could play a role in the major decline of cognitive function. Diabetes control should be determined by the level of fragility, physical dependence and cognitive status, adjusting glycemic control objectives to this situation. In addition, the healthcare teams at home nursing centers should receive specific training to deal with diabetes and cognitive impairment that is adapted to this stage of the life cycle.

\section{Article Information}

*Correspondence: Miguel Ángel Carreiro Alonso, PhD, Santiago de Compostela University, Xesta n¹2 A Lama. 36836. Pontevedra. Spain. Tel: 34-648-779-241; Email: miguelangel.carreiro@gmail.com

Received: Aug. 25, 2017; Accepted: Oct. 16, 2017; Published: Dec. 16, 2017

\section{DOI: 10.24983/scitemed.nnr.2017.00047}

Copyright (c) 2017 The Author (s). This is an open-access article distributed under the terms of the Creative Commons Attribution 4.0 International License (CC-BY).

Funding: This research did not receive any specific grant from funding agencies in the public, commercial, or not-for-profit sectors.

Conflict of Interest: The authors declare no financial and personal relationships with other people or organizations with any interest financial or otherwise in the subject matter discussed in this manuscript.

\section{Acknowledgements}

The authors wish to thank to the residents and professionals who have participated in this study, and managers of the centers for their collaboration.

\section{Keywords}

Aging; cognitive dysfunction; diabetes mellitus; frail elderly, hypoglycemia.

\section{References}

1. Deary IJ, Corley J, Gow AJ, et al. Age-associated cognitive decline. British Medical Bulletin 2009;92:135-152.

2. Goday A, Gabriel R, Ascaso JF, et al. [Cardiovascular risk in subjects with high probability of metabolic syndrome and insulin resistance. DESIRE study]. Revista Clínica Espanõla 2008;208:377-385.

3. Neumiller JJ, Odegard PS, Haines ST. Weighing the potential benefits and risks of antidiabetic agents in older adults. Diabetes Spectrum 2012;25:172-179.

4. Biessels GJ. Brain MRI correlates of cognitive dysfunction in type 2 diabetes: the needle recovered from the haystack? Diabetes Care 2013:36:3855-3856.
5. Bo M, Gallo S, Zanocchi M, et al. Prevalence, clinical correlates, and use of glucose-lowering drugs among older patients with type 2 diabetes living in long-term care facilities. Journal of Diabetes Research 2015.

6. Abdelhafiz AH, Rodríguez-Mañas L, Morley JE, Sinclair AJ. Hypoglycemia in older people - a less well recognized risk factor for frailty. Aging and Disease 2015;6:156-157.

7. Kodl CT, Seaquist ER. Cognitive dysfunction and diabetes mellitus. Endocrine Reviews 2008:29:494-511.

8. Gul A, Sehar M, Jawad U. Relationship between neuropsychological functioning, behavioral inhibition, and glycemic control in type $2 \mathrm{di}$ abetes: findings from task-switching study. Chinese Medical Journal 2017;130:487-489.

9. American Geriatrics Society Expert Panel on Care of Older Adults with Diabetes Mellitus. Guidelines abstracted from the American Geriatrics Society guidelines for improving the care of older adults with Diabetes Mellitus: 2013 update. Journal of the American Geriatrics Society 2013.

10. American Diabetes Association. 5. Glycemic targets. Diabetes Care 2016;39:S39-S46.

11. American Diabetes Association. Classification and diagnosis of diabetes Diabetes Care 2016;39:S13-S22.

12. Formiga F, Ferrer A, Padrós G, et al. Diabetes mellitus as a risk factor for functional and cognitive decline in very old people: the Octabaix study. Journal of the American Medical Directors Association 2014;15:924-928.

13. Sinclair AJ, Conroy SP, Bayer AJ. Impact of diabetes on physical function in older people. Diabetes Care 2008;31:233-235.

14. Travis SS, Buchanan RJ, Wang S, Kim M. Analyses of nursing home residents with diabetes at admission. Journal of the American Medical Directors Association 2004;5:320-327.

15. Pfeiffer E. A short portable mental status questionnaire for the assessment of organic brain deficit in elderly patients. Journal of the American Geriatrics Society 1975;23:433-441.

16. Mahoney F, Barthel D. Functional evaluation: the Barthel Index. Maryland State Medical Journal 1965;14:61-65.

17. The DECODE Study Group. Age- and sex-specific prevalences of diabetes and impaired glucose regulation in 13 European cohorts. Diabetes Care 2003:26:61-69.

18. de Souto Barreto P, Sanz C, Vellas B, Lapeyre-Mestre M, Rolland Y. Drug treatment for diabetes in nursing home residents. Diabetic Medicine : A Journal of the British Diabetic Association 2014;31:570-576.

19. Andreassen LM, Sandberg S, Kristensen GBB, Sølvik UØ, Kjome RLS. Nursing home patients with diabetes: Prevalence, drug treatment and glycemic control. Diabetes Research and Clinical Practice 2014;105:102-109.

20. Morley JE, Adams EV. Rapid geriatric assessment. Journal of the American Medical Directors Association 2015;16:808-812.

21. Bennett K. Diabetes in older people. Clinical Medicine : Journal of the Royal College of Physicians of London 2015;15:465-467.

22. Mukherjee E, Carroll R, Matfin G. Endocrine and metabolic emergencies: hypoglycaemia. Therapeutic Advances in Endocrinology and Metabolism 2011;2:81-93.

23. Bruce DG, Davis WA, Casey GP, et al. Predictors of cognitive decline in older individuals with diabetes. Diabetes Care 2008;31:2103-2107.

24. Frier BM. Hypoglycaemia in diabetes mellitus: epidemiology and clinical implications. Nature Reviews Endocrinology 2014;10:711-722.

25. Bordier L, Doucet J, Boudet J, Bauduceau B. Update on cognitive decline and dementia in elderly patients with diabetes. Diabetes \& Metabolism 2014;40:331-337.

26. Beverly EA, Weinger K. Response to comment on: Beverly, et al. Do older adults aged 60-75 years benefit from diabetes behavioral interventions? Diabetes Care 2013;36:1501-1506. Diabetes Care 2013;36:e126.

27. Mattishent K, Loke YK. Bi-directional interaction between hypoglycaemia and cognitive impairment in elderly patients treated with glucose-lowering agents: a systematic review and meta-analysis. $\mathrm{Di}$ abetes, Obesity and Metabolism 2016;18:135-141. 